\title{
Agrotóxicos e meio ambiente: inserção do tẹma na escola através de uma abordagem interdisciplinar
}

\author{
Agrochemicals and Environment: insertion of the topic in school through as \\ interdisciplinary approach
}

\author{
Martha Bohrer Adaime ${ }^{1}$, Marcia Palma Botega ${ }^{2}$, Osmar Damian Prestes ${ }^{3}$, Renato Zanella ${ }^{4}$ \\ ${ }^{1}$ Universidade Federal de Santa Maria, RS, Brasil
}

\begin{abstract}
Resumo
O trabalhador rural e sua família estão expostos à diversas situações de risco à saúde durante o desempenho de suas atividades no campo. A contaminação humana e ambiental por agrotóxicos está longe de ser um problema simples, muito em parte pela diversidade de determinantes de ordem social, econômica e cultural, que o permeiam. Diante da complexidade do tema, o objetivo principal deste estudo foi capacitar jovens estudantes do Ensino Médio, filhos de pequenos agricultores, da zona rural do município de Agudo-RS, para atuarem como multiplicadores dos conhecimentos sobre a importância da utilização correta de agrotóxicos e os riscos que os mesmos podem causar à saúde humana e ao meio ambiente, enfatizando a importância do uso das Boas Práticas Agrícolas. Utilizou-se uma abordagem interdisciplinar com o objetivo de situar os alunos no ambiente social e cultural. Considerando que este trabalho foi elaborado com o propósito de formar jovens multiplicadores de informações, as principais estratégias didáticas utilizadas foram a leitura e interpretação de textos, discussão em grupos, estudo do meio ambiente, projeto coletivo e interação com a comunidade, que exigiram a participação ativa dos alunos no processo de capacitação e aprendizagem.
\end{abstract}

Palavras-chave: Agrotóxicos, jovens multiplicadores, boas práticas agrícolas.

\begin{abstract}
The rural workers and their families are exposed to many risk situations concerning their health during the performance of their activities in the field. Human and environmental contamination by agrochemicals is far from being a simple problem, in large part due to the diversity of social, economical and cultural determinants that permeate them. Given the complexity of the topic, the main objective of this study was to capacitate young high school students, coming from families of small farmers, from the rural area of the city of Agudo-RS, to act as multipliers of knowledge on the importance of the correct use of agrochemicals and the risks they may cause to human health and the environment, highlighting the importance of the use of Good Farming Practices. An interdisciplinary approach was used with the objective of situating the students in the social and cultural environment. Considering that this study was elaborated with the purpose of training young multipliers of information, the main didactic strategies used were reading and interpretation of texts, group discussions, study of the environment, collective project and interaction with the community, which demanded the active participation of the students in the capacitating and learning processes.
\end{abstract}

Keywords: Agrochemicals, young multipliers, good farming practices. 


\section{Introdução}

A contaminação humana e ambiental por agrotóxicos está longe de ser um problema simples, muito em parte pela diversidade de determinantes de ordens social, econômica e cultural, que o permeiam (SILVA et al., 2013). Nas pequenas comunidades rurais, o regime de agricultura familiar é predominante, onde todos integrantes da família participam de alguma forma do processo de trabalho.

A exposição aos agrotóxicos pode ser de inúmeras formas, que incluem desde a aplicação dos produtos, o trabalho na colheita, a lavagem de roupas contaminadas e a manipulação de embalagens vazias (BRITO, 2005).

O município de Agudo-RS, foco desse estudo, está localizado na região central do Estado do Rio Grande do Sul e possui uma população estimada em 16.722 habitantes, tendo uma densidade demográfica de 31,19 $\mathrm{hab} / \mathrm{km}^{2}$ e área de 536,12 $\mathrm{km}^{2}$ (IBGE, 2010). A área é constituída por pequenas propriedades rurais onde predomina a agricultura familiar, cujas principais culturas são: tabaco, arroz e morango.

A produção de tabaco na região sul do Brasil, mais precisamente no Estado do Rio Grande do Sul (RS), exerce grande importância na atividade econômica e social. Os agricultores que trabalham nas lavouras de tabaco estão em constante contato com a planta e consequentemente expostos aos agrotóxicos naturais e sintéticos relacionados à cultura (SILVA et al., 2013).

O sistema de produção utilizado pelos agricultores no cultivo do tabaco demanda mão de obra intensiva e exige uma quantidade considerável de agrotóxicos. Os problemas mais conhecidos em relação a este sistema de produção incluem riscos à saúde e danos ao meio ambiente, resultantes do uso inapropriado de agrotóxicos e do desmatamento, bem como do emprego de mão de obra infantil associado ao uso extensivo de trabalho familiar no cultivo do tabaco (VARGAS e BONATO, 2007).

Sabendo-se que na região estudada, os produtores estão constantemente expostos aos agrotóxicos, definiu-se centrar o estudo sobre o tema em questão, nas concepções dos jovens, que trabalham com seus familiares na cadeia produtiva do tabaco. Para tanto realizou-se um ciclo de palestras e a elaboração de material didático com os estudantes envolvidos, de forma presencial, na escola onde o estudo foi desenvolvido, como estratégia de formação para que posteriormente multiplicassem estas informações junto a comunidade onde estão inseridos.

\subsection{Educação ambiental}

Desenvolver questões ambientais dentro das escolas brasileiras ainda tem sido um processo lento, em grande parte devido à resistência das partes envolvidas, inclusive dos educadores, em substituir hábitos e conceitos adquiridos em uma sociedade desenvolvimentista, porém despreocupada com os resíduos do seu processo de industrialização (BIANCHI e MELO, 2009).

A lei brasileira n⿳0 9.795/99 que dispõe sobre a Educação Ambiental, institui a Política Nacional de Educação Ambiental e dá outras providências, define no capítulo I, no artigo $1^{\circ}$, o termo educação ambiental:

“Entende-se por educação ambiental os processos por meio dos quais o indivíduo e a coletividade constroem valores sociais, conhecimentos, habilidades, atitudes e competências voltadas para a conservação do meio ambiente, bem como o uso comum do povo, essencial a sadia qualidade de vida e sustentabilidade."

Desde 1997, com a revisão dos currículos da educação, pelo Ministério da Educação - MEC, os professores e especialistas em educação brasileiros obtiveram um instrumento oficial de orientação à implementação da Educação Ambiental nas escolas: os Parâmetros Curriculares Nacionais - PCNs (BRASIL, 1997). A escola é um espaço estratégico e privilegiado para promover a Educação Ambiental, porque pode oferecer meios efetivos para que os alunos compreendam os fenômenos naturais, as ações humanas inerentes ao seu processo histórico de desenvolvimento sócio-tecnológico e suas consequências para o planeta (BIANCHI e MELO, 2009).

\subsection{Jovem multiplicador}

Os jovens que vivem no meio rural convivem direta ou indiretamente com a agricultura, na maioria das vezes trabalham na plantação e na colheita, porém não tem o hábito de questionar a forma pela qual estas são realizadas. Uma questão que deve ser colocada em destaque quando falamos de agricultura é a utilização dos agrotóxicos, com todos os riscos de contaminação dos alimentos e do meio ambiente, nela envolvidos (GREGOLIS et al., 2012). A educação é um processo potencial que nos habilita como indivíduos e como comunidades a compreendermos a nós mesmos e aos outros e as nossas ligações com o meio ambiente social e natural de forma mais ampla. Neste sentido, a educação é um importante agente de transformação para o desenvolvimento sustentável, aumentando a capacidade das pessoas de transformar sua visão de sociedade em realidade (UNESCO, 2007). Na educação ambiental há grande diferença entre informar e formar. O processo educativo não se resume a transmitir informações sobre o que fazer para melhorar o ambiente, mas é preciso investir na formação de pessoas que concretamente enfrentem a problemática ambiental e comprometam-se com as mudanças necessárias à qualidade de vida no ambiente de forma autônoma e responsável (JANKE e TOZONI-REIS, 2008). A formação de jovens multiplicadores atua como instrumento pedagógico do desenvolvimento, tanto local, como regional de forma integrada e sustentável. É importante que se leve em consideração a riqueza de conhecimentos das experiências diárias desses jovens, envolvendo práticas relacionadas ao dia a dia de suas famílias, incentivando e fortalecendo a agricultura fa- 
miliar (BRASIL, 2007).

Considerando a singularidade das vinculações que cada um estabelece em função de suas experiências e saberes torna-se necessário instituir processos de aprendizagem que contemplem as necessidades do camponês que estabelece uma relação direta com o ambiente (PESSANHA et al., 2002). A ideia de formar jovens multiplicadores surge da necessidade de diminuir a distância existente entre o meio rural e os conhecimentos do meio universitário, como forma de facilitar o intercâmbio de informações, identificando os problemas atuais dos jovens no campo e a troca de experiências com a universidade e o contexto onde estão inseridos. Diante da complexidade do tema e buscando a contextualização da Educação Ambiental, o objetivo principal deste estudo foi capacitar jovens, filhos de pequenos agricultores, da zona rural do município de Agudo-RS, alunos do ensino médio da Escola Estadual de Educação Básica Professor Willy Roos. Para atuarem como multiplicadores dos conhecimentos sobre a importância da utilização correta de agrotóxicos e os problemas que os mesmos podem causar à saúde do homem e do meio ambiente, enfatizando as Boas Práticas Agrícolas.

\section{Metodologia}

Considerando o propósito desta pesquisa, foi realizado um estudo de caso, numa abordagem qualitativa e quantitativa. A combinação dessas metodologias permitiu a investigação das práticas do uso dos agrotóxicos, dos impactos causados na saúde e no ambiente, associando-os com dados subjetivos da percepção que os jovens estudantes que participaram do estudo têm sobre essas práticas.

Esta pesquisa procurou demonstrar quais as concepções dos estudantes sobre o uso dos agrotóxicos. Segundo Santos (2002), o estudo de caso é a seleção de um objeto de pesquisa restrito, com o objetivo de aprofundar-lhe os aspectos característicos. Os benefícios do estudo objetivaram proporcionar uma melhor qualidade de vida para a população envolvida. Ainda, em relação aos princípios metodológicos utilizados, para Ludke \& André (1986), a pesquisa de abordagem qualitativa retrata situações simples e específicas até situações complexas e abstratas de forma completa e profunda.

O trabalho de campo foi realizado na Escola Estadual de Educação Básica Professor Willy Roos, envolvendo 25 alunos do Ensino Médio, de idades entre 14 e 18 anos, selecionados de maneira aleatória. Os alunos foram selecionados de maneira aleatória e por serem filhos de pequenos agricultores, que trabalham em regime de agricultura familiar e produzem tabaco, para atuarem como multiplicadores dos conhecimentos sobre a importância da utilização correta dos agrotóxicos e os riscos que o mau uso dos mesmos pode causar a saúde do homem e ao meio ambiente.
Aplicou-se um questionário objetivo em sala de aula, sem identificação e com devolução imediata, para a realização do levantamento do nível de conhecimento, as crenças e as percepções dos estudantes, sobre o risco da exposição aos agrotóxicos. Foi aplicado na fase inicial para melhor compreender as concepções dos jovens, objetos do estudo.

\section{Resultados e Discussão}

Sequência de atividades de formação dos jovens multiplicadores:

O ciclo de palestras e a elaboração de material didático foram realizados, de forma presencial, na escola onde o estudo foi desenvolvido.

\subsection{Ciclo de palestras}

As atividades foram iniciadas realizando-se um ciclo de palestras sobre a temática: agrotóxicos como forma de aproximar os conhecimentos prévios dos alunos aos conhecimentos científicos. As apresentações foram realizadas de forma que os alunos fossem aprofundando seus conhecimentos sobre o assunto e estabelecendo a relação de confiança com a pesquisadora.

No desenvolvimento desta etapa, buscando-se considerar realmente o aprendizado, aplicaram-se atividades no decorrer e/ou final de cada palestra, para avaliar os conhecimentos adquiridos, utilizaram-se estes instrumentos para acompanhar a aprendizagem dos alunos, buscando compreender até que ponto os objetivos propostos durante estas intervenções, haviam sido atingidos.

No ciclo de palestras foram abordados os seguintes temas: “O jovem como multiplicador das Boas Práticas Agrícolas na zona rural do Município de Agudo-RS, Brasil"; "Os agrotóxicos, o homem e o meio ambiente"; "Classes toxicológicas dos agrotóxicos utilizados na plantação de tabaco".

\subsection{Jogo didático, blog, folder e cartilha}

A partir do ciclo de palestras, desenvolveu-se um jogo didático com a participação direta dos alunos, um blog, um folder educativo e uma cartilha para envolver os alunos com o tema de preservação da saúde e da natureza, criando estratégias para multiplicar os conhecimentos adquiridos durante as palestras em suas famílias e na comunidade.

\subsection{Jogo didático}

O jogo foi elaborado tomando como base os seguintes assuntos: Agrotóxicos, Boas Práticas Agrícolas e Meio Ambiente. O tabuleiro foi elaborado para que os alunos tivessem a visão de todas as etapas para o uso correto dos agrotóxicos, que vai desde o momento da aquisição 


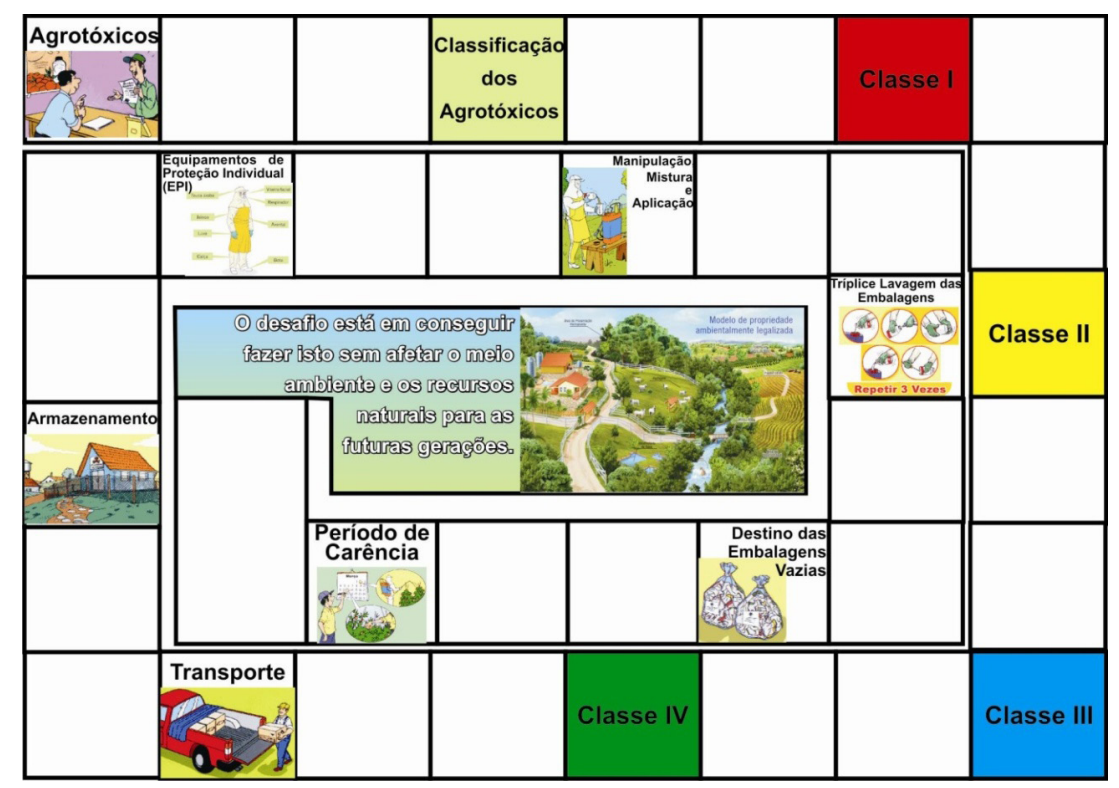

Figura 1- Tabuleiro do jogo.

do produto até o destino final das embalagens vazias. Demonstraram-se de forma simplificada, os principais cuidados que devem ser tomados ao manusear os agrotóxicos.

Composição do jogo: um tabuleiro (figura 1), um dado, quatro pinos de cores diferentes e treze fichas com explicações referentes a cada estação que compõem o tabuleiro. $\mathrm{O}$ tabuleiro foi elaborado para que os alunos tivessem a visão de todas as etapas para o uso correto dos agrotóxicos, que vai desde o momento da aquisição do produto até o destino final das embalagens vazias.

A dinâmica do jogo foi composta por um moderador e quatro jogadores. O moderador tinha a posse das fichas e, portanto as informações corretas e os jogadores movimentavam os pinos conforme o número indicado no dado. Se acertassem, o pino avançava e se errassem deveriam retroceder, também conforme o número de casas que o dado indicava. Considerando as informações que constavam nas fichas, o jogador que chegasse primeiro era o vencedor.

Após a atividade perguntou-se aos jogadores: "O que você aprendeu com o jogo?". De uma maneira geral os alunos mencionaram os cuidados que devem ser tomados ao manusear os agrotóxicos, bem como os riscos que o mau uso dos mesmos pode causar ao homem e ao meio ambiente. Verificou-se que o propósito desta atividade foi atingido, uma vez que os alunos demonstraram ter adquirido novas informações e consciência sobre o tema.

Quando foi perguntado: O que você aprendeu com o jogo? As respostas mais frequentes foram:

Aluno 1: "Aprendi que os agrotóxicos prejudicam toda forma de vida."

Aluno 2: "A como me proteger."
Aluno 3:"Algumas palavras e seus significados das quais não sabíamos."

Aluno 4:"Aprendi que não pensamos nas consequências que causamos no meio ambiente."

Aluno 5:"Aprendi muitas coisas sobre agrotóxicos e sobre os problemas que eles podem trazer as pessoas."

Pode-se observar que os alunos tiveram um bom entendimento das regras do jogo, notou-se que os membros das equipes estavam empenhados em vencer, comprovando-se que com atividades lúdicas é possível motivar a aprendizagem, o envolvimento e o entrosamento entre os alunos. Os professores avaliaram positivamente a aplicabilidade e eficiência do jogo, pois o mesmo proporcionou a aprendizagem de forma lúdica e eficiente.

\subsection{Blog}

Criou-se o blog "Turma Antenada", para que os assuntos referentes ao uso de agrotóxicos e meio ambiente, trabalhados em sala de aula, pudessem ser divulgados permitindo a interação dos usuários, além de estimular o acesso dos alunos ao ambiente virtual. Um novo tempo, um novo espaço e outras maneiras de pensar e fazer educação são exigidos pela sociedade contemporânea (ARAÚJO, 2009). Blogs educativos aparecem como alternativas que propõem abordagens diversas, que capacitam os usuários na interação com o conhecimento e divulgação das próprias construções. A elaboração do blog partiu da organização de informações coletadas nas revistas on-line Ciência Hoje On-Line (MARCOLINI, 2009; BELO, 2008; LEAL, 2008) e Nova Escola (ENGELSTEIN, 2007; MENEZES, 2009). 


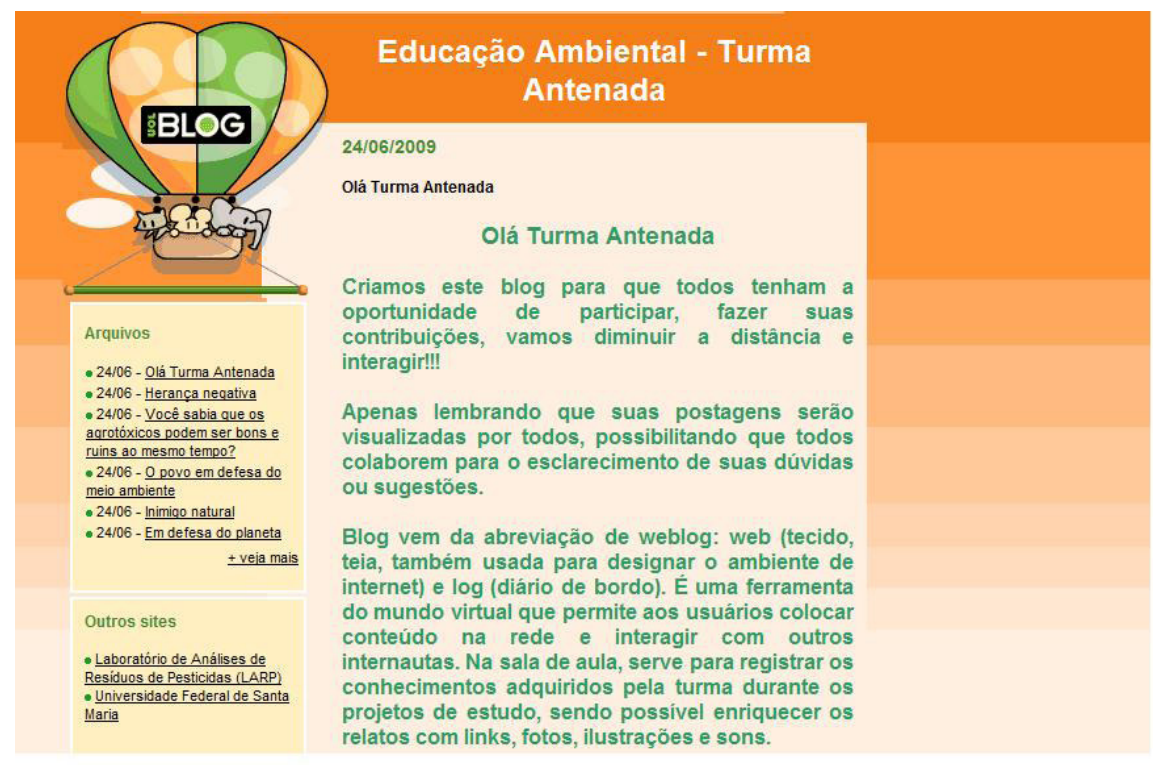

Figura 2 - Criada pelo autor, disponível em http://mambiente.zip.net.

Para acessar o blog e realizar a atividade proposta utilizou-se a sala de informática da escola, onde os alunos foram divididos em duplas nos computadores. Realizou-se então a leitura das reportagens e após, foram feitos comentários das duplas, sobre suas impressões a respeito do que haviam lido.

O blog (figura 2) foi estruturado de tal forma que, através da página principal, os alunos pudessem acessar a apresentação e fragmentos das reportagens intituladas: "Herança negativa" (MARCOLINI, 2009); "Você sabia que os agrotóxicos podem ser bons e ruins ao mesmo tempo?" (BELO, 2008); "O povo em defesa do meio ambiente" (LEAL, 2008); "Inimigo natural" (ENGELSTEIN, 2007) e "Em defesa do planeta" (MENEZES, 2009).

Embora a navegabilidade do blog fosse simples a maioria dos alunos encontrou dificuldades, em virtude de não terem acesso rotineiramente ao computador e a internet. Para a grande maioria, esta foi a primeira oportunidade de acesso ao computador e a internet e, por isso, a atividade tomou outras proporções.

Foi necessário ensinar passo a passo (como utilizar o mouse, navegar na internet etc.) e mesmo assim, observou-se os alunos motivados, a medida que liam suas postagens no blog. As opiniões dos alunos a seguir confirmam a importância da participação ativa no blog:

Aluno 1: "Achamos legal que estava escrito sobre o blog que vocês criaram para nossa turma pois, é muito interessante o trabalho que estão realizando conosco."

Aluno 2: "A participação da sociedade é muito importante nas campanhas contra o uso de agrotóxicos."

Aluno 3: “É interessante saber como os agrotóxicos afetam o ser humano que comprova isto é a parte onde fala dos elefantes marinhos que foram contaminados por estes agrotóxicos e acabaram transmitindo para seus filhotes."

Aluno 4: "Nós que moramos no interior nem percebemos que não prejudicamos somente a nós mesmos, como também a pequenos seres como as minhoquinhas e os vegetais menores."

Aluno 5: “Ao mesmo tempo que previne as plantas do ataque das pragas, o agrotóxico também pode ser prejudicial a vida dos vegetais, dessa forma, ao mesmo tempo que previne causa impacto aos mesmos."

Portanto, foi uma oportunidade de terem o primeiro contato com esta tecnologia.

\subsection{Folder}

Elaborou-se o folder educativo intitulado "Agrotóxicos e Meio Ambiente" (figura 3), como uma forma de proporcionar a circulação de informações, por ser um recurso rico em imagens e palavras. $\mathrm{O}$ folder foi elaborado a partir de desenhos e informações geradas pelos alunos para divulgar o desenvolvimento do trabalho referente ao uso de agrotóxicos e das Boas Práticas Agrícolas e posteriormente foi distribuído pelos próprios alunos.

O conteúdo do folder foi adaptado e ilustrado pelos alunos e está subdividido da seguinte forma: Aquisição dos agrotóxicos; Transporte; Armazenamento; Cuidados no manuseio; Período de carência; Destino final das embalagens e Higiene.

Após a elaboração e impressão, apresentou-se o material finalizado para a turma. Então, iniciou-se o trabalho de divulgação, em um primeiro momento através de uma visita na Secretaria Municipal de Educação do Município. Para esta visita, foram escolhidos por votação, dois representantes da turma que foram 


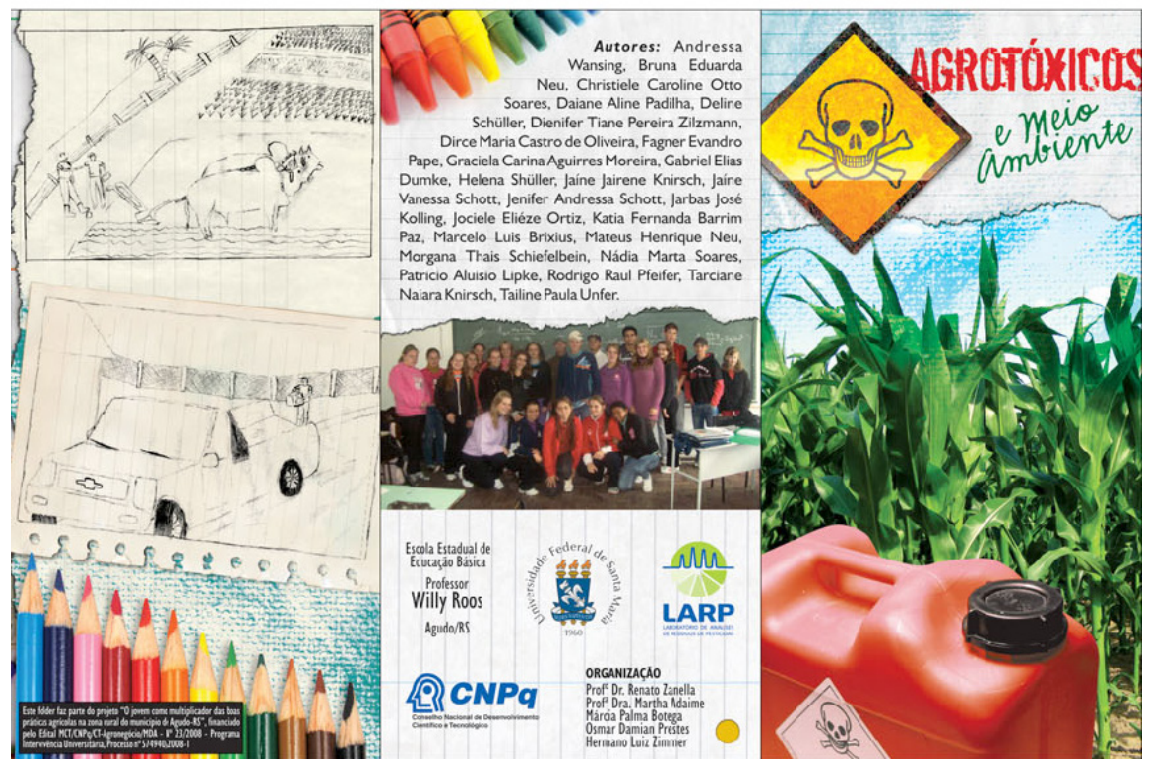

Figura 3 - Folder "Agrotóxicos e meio ambiente".

acompanhados pela diretora da escola e pela pesquisadora. Foi realizada a explanação da principal função do folder: capacitar os alunos na elaboração e divulgação do material informativo.

No segundo momento, realizou-se a distribuição do folder no centro da cidade de Agudo-RS. Nesta abordagem os alunos mostraram-se entusiasmados, pois tiveram oportunidade de interagir com as pessoas, através do material que eles mesmos haviam elaborado, e puderam colocar em prática tudo o que aprenderam durante a capacitação.

Em um terceiro momento realizou-se a distribuição do folder em desfile cívico no centro da cidade que teve grande participação da população oriunda do interior do município, sendo possível mais uma vez, realizar a interação dos estudantes com a comunidade.

\subsection{Cartilha}

A culminância de todas as atividades foi a elaboração de uma cartilha (figura 4), pelos alunos, criada em forma de projeto coletivo, composta por histórias criadas pelos alunos, envolvendo a temática: agrotóxicos e meio ambiente. A turma foi dividida em duplas e trios para criação de histórias dirigidas ao público infantil, levando-se em conta que a abordagem deveria ser voltada à crianças do $1^{\circ}$ ao $4^{\circ}$ ano do Ensino Fundamental.

Para elaborar a cartilha, partiu-se da leitura e exploração da narrativa "A Vaca e a Aranha" (SCARPELO, 2010), que traz em sua história o tema agrotóxicos e produtos orgânicos. A intenção foi incentivar que os alunos criassem seus próprios personagens, elaborando histórias voltadas ao público infantil. Foram criadas 13 histórias, cujos títulos são: $\mathrm{O}$ cavalo e o papagaio; $\mathrm{O}$ rei da horta; A porca e a galinha; O carneiro, o porco e a amiga abelha; O papagaio e a abelha; O milho e o fumo; Pape e Carlito; A ovelha preguiça e a galinha metida; O líder José; Paraíso; A cabrita e a aranha; Filosofia de uma criança e Chácara Willy Roos.

Deste modo os alunos puderam observar a diversidade de aspectos que envolvem o tema, os personagens, bem como os aspectos referentes à criação de uma história. O resultado foi surpreendente, a produção textual foi coerente e estruturada, com desenvolvimento e coesão pertinentes à temática. Observou-se uma cartilha feita com muito investimento por parte dos alunos, material que servirá de instrumento para a educação e divulgação. Os alunos tiveram a oportunidade de ampliar a sua compreensão sobre a temática e refletir a respeito da intervenção sobre a realidade que os contextualiza, privilegiando o desenvolvimento da sua autonomia.

A cartilha educativa, elaborada de forma lúdica, com histórias contendo vocabulário coerente, convidativo de fácil leitura e entendimento atinge o público infantil e indiretamente suas famílias.

As histórias estão acompanhadas de ilustrações porque as mesmas facilitam a percepção de detalhes, ampliando o tamanho real dos personagens, proporcionando a visualização imediata e contextualizada do tema, bem como a possibilidade de usá-las para pintura.

A agricultura é um ciclo familiar na comunidade estudada, onde os hábitos e conhecimentos e/ou desconhecimentos são elaborados a partir da cultura familiar onde todos participam de um modo ou de outro, seja no processo de plantio, no combate as pragas ou na colheita. Existe uma vocação agrícola na região do estudo, por isso, é importante ressaltar a necessidade de abordagens integradas e interdisciplinares, relacionadas à educação ambiental, com ênfase em agrotóxicos e riscos de intoxicação. 


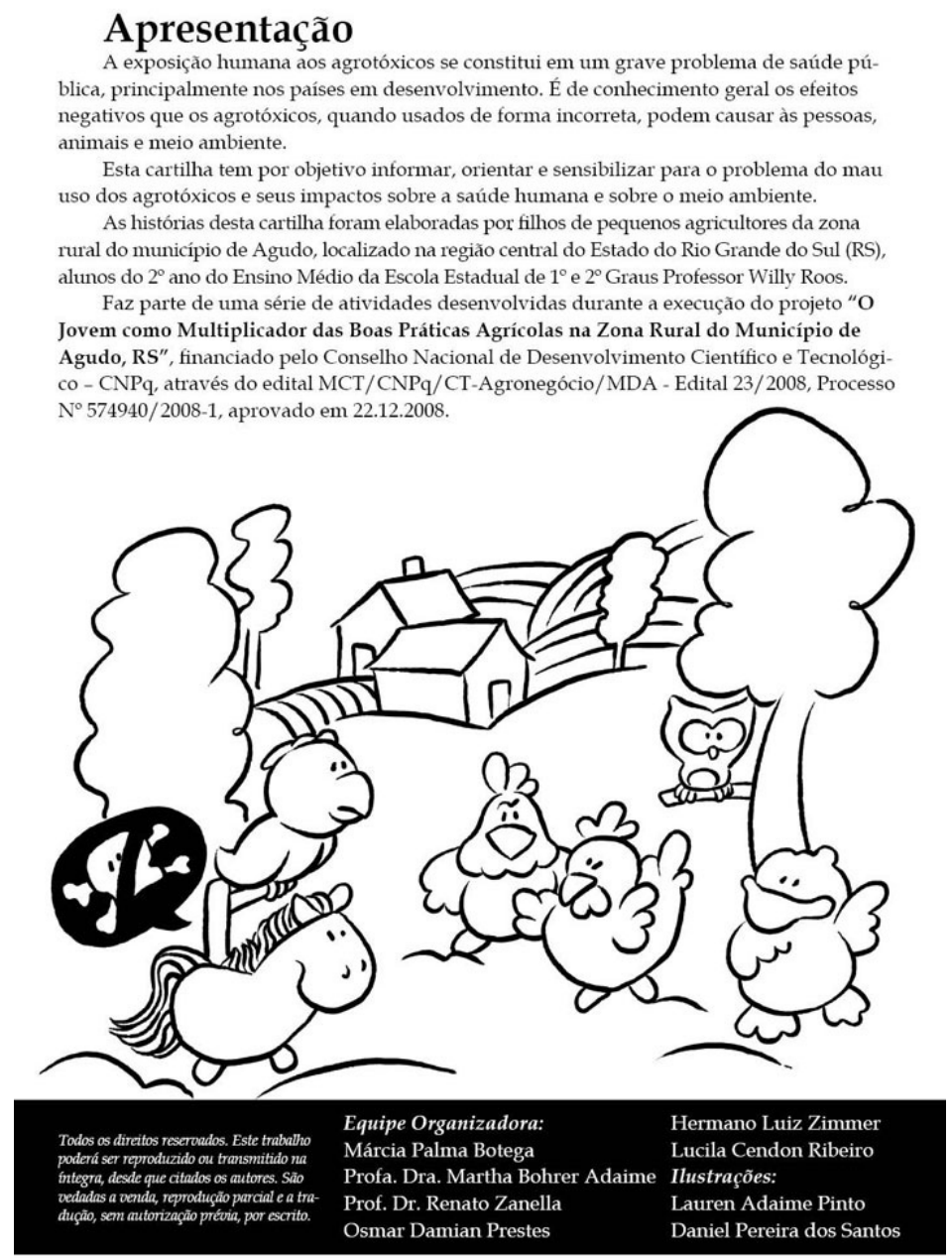

Esta cartilha e outros materiais relacionados poderão ser visualizados em nosso site: www:ufsm.br/larp

Figura 4- Apresentação da cartilha "Agrotóxicos e Meio Ambiente".

A realidade do trabalho rural em Agudo-RS é similar a maioria dos municípios agrícolas brasileiros e causa importantes impactos sobre a saúde dos trabalhadores envolvidos, ao meio ambiente e a própria agricultura. $\mathrm{O}$ agricultor despreparado comete erros ao fazer uso incorreto dos agrotóxicos, promovendo a contaminação do solo, das águas de superfície e subterrâneas, levando ao comprometimento da saúde e do meio ambiente. A inserção de crianças e adolescentes no processo de agricultura familiar e a vocação agrícola observada na região influenciam fortemente a opção profissional das crianças e adolescentes, tornando-se imprescindível investir na educação para a saúde e na formação da consciência ambiental destes alunos, favorecendo a troca entre o conhecimento científico e o saber popular.

Ao longo do desenvolvimento da pesquisa observouse a necessidade e importância da pesquisa e construção de materiais didáticos, como forma de propor práticas diferenciadas para refletir a educação no campo. Considerando que este trabalho foi elaborado com o propósito de formar jovens multiplicadores de informações, as estratégias didáticas utilizadas: leitura e interpretação de textos, discussão em grupos, estudo do meio ambiente, projeto coletivo, interação com a comunidade e intervivência universitária, exigiram a participação ativa dos alunos no processo de capacitação e aprendizagem.

Os dados levantados, trazem um diagnóstico sobre o impacto causado pela utilização intensiva de agrotóxicos na população envolvida no processo de cultivo do tabaco, considerando-se que a grande maioria dos alunos está exposta a estas substâncias, desde muito cedo.

Diante dos resultados e discussão apresentados neste estudo, é importante destacar a necessidade de campanhas direcionadas para a educação ambiental da população estudada, com ênfase nas Boas Práticas Agrícolas, devido ao uso inadequado dos agrotóxicos e da proximidade das moradias, em relação às áreas de cultivo de tabaco.

Ao final desta experiência de ensino, acreditamos que a melhoria depende, parcialmente, da criação de espaços de formação para os agricultores, pois percebeu-se o interesse em promover o desenvolvimento sustentável em suas comunidades, que visem minimizar o impacto causado pelo uso dos agrotóxicos. 


\section{Conclusão}

Verificou-se que a utilização de materiais didáticos diferenciados como jogo, blog, folder e cartilha para as ações de capacitação e difusão do conhecimento, possibilitaram aos alunos a reflexão sobre o tema, sob outra perspectiva, que não apenas a do trabalho, mas sob a ótica da relevância do seu papel, como jovens multiplicadores, bem informados, junto à comunidade em que vivem.

A elaboração das histórias para a criação da cartilha foi o momento onde foi possível comparar a evolução dos conhecimentos dos alunos, visto que a maioria conseguiu absorver as informações científicas pertinentes ao tema.

\section{Referências}

ARAÚJO, M. C. M. U. Potencialidades do uso do blog na educação. Dissertação de Mestrado. 2009. 207 f. Universidade Federal do Rio Grande do Norte, Natal, 2009.

BELO, M. Você sabia que os agrotóxicos podem ser bons e ruins ao mesmo tempo? Ciência Hoje das Crianças. Em: $<$ http://chc.cienciahoje.uol.com.br/ multimidia/revistas/reduzidas/188/files/assets/seo/ page4.html >. Acesso em: 8 de março de 2013.

BIANCHI, C.; MELO, W. Desenvolvimento de um projeto de ação pedagógica para conscientização ambiental com alunos de 9$^{\circ}$ ano do Ensino Fundamental. Revista Electrónica de Enseñanza de las Ciencias, v. 8 n. 3, 976 - 1003. 2009.

BRASIL. Política Nacional de Educação Ambiental (PNEA). 1999.

\section{BRASIL, MINISTÉRIO DA EDUCAÇÃO.}

Coordenação Geral de Educação Ambiental: Ministério do Meio Ambiente, Departamento de Educação Ambiental : UNESCO, 248 p., 2007.

ENGELSTEIN, M. Inimigo natural. Em: $<\underline{\text { http:// }}$ revistaescola.abril.com.br/ciencias/praticapedagogica/defesa-planeta-426591.shtml>. Acesso em: 17 de novembro de 2013.

GREGOLIS, T. B. L.; PINTO, W. J. E PERES, FREDERICO. Percepção de riscos do uso de agrotóxicos por trabalhadores da agricultura familiar do município de Rio Branco, Revista Brasileira de Saúde Ocupacional, vol.37, n.125, pp. 99-113, 2012.

IBGE, Instituto Brasileiro de Geografia e Estatística. Em: $<$ http://www.ibge.gov.br/cidadesat/ topwindow.htm?1>. Acesso em: 20 de novembro de 2013.

JANKE, N.; TOZONI-REIS, M. F. C. Produção coletiva de conhecimentos sobre qualidade de vida: por uma educação ambiental participativa e emancipatória. Ciência \& Educação, v. 14, n. 1, p. 147-157, 2008.

Leal, T. (2009). O povo em defesa do meio ambiente. Em: <http://cienciahoje.uol.com.br/noticias/ ecologia-e-meio-ambiente/o-povo-em-defesa-domeio-ambiente>. Acesso em: 8 de março de 2013.

LUDKE, M.A.; MARLI, E. D. A. Pesquisa em educação: abordagens qualitativas. São Paulo: EPU, 100p., 1986.

MARCOLINI, B. Herança negativa. Em: http://cienciahoje.uol.com.br/noticias/ ecologia-e-meio-ambiente/herancanegativa/?searchterm $=$ Heran $\% \mathrm{C} 3 \% \mathrm{~A} 7 \mathrm{a} \% 20$ negativa . Acesso em: 8 de março de 2013.

MENEZES, D. Em defesa do planeta. Em: $<$ http:// revistaescola.abril.com.br/ensino-medio/inimigonatural-427358.shtml>. Acesso em: 8 de março de 2013.

PESSANHA, L. D. R. O sentido brasileiro da segurança alimentar. Mundo rural e cultura. Rio de Janeiro: Mauad, p. 263-284, 2002.

SANTOS, A. R. Metodologia científica: a construção do conhecimento. Rio de Janeiro: DP\&A, 2002.

SCARPELO, V. Histórias que Encantam Crianças. São Paulo: Grupo Direcional. 2010.

SILVA, F. R. Genotoxicity of Nicotiana tabacum leaves on Helix aspersa. Genetics and Molecular Biology, vol.36, n.2, P. 269-275. Em: <http://www.scielo.br/ $\mathrm{pdf} / \mathrm{gmb} / \mathrm{v} 36 \mathrm{n} 2 / 2012-358 . \mathrm{pdf}>.2013$.

UNESCO. Década das Nações Unidas para um desenvolvimento sustentável, 2005-2014: documento final do esquema internacional de implantação. Brasília. 2005.

VARGAS, M.; BONATO, A. (2007). Cultivo do Tabaco, Agricultura Familiar e Estratégias de Diversificação no Brasil, Secretaria de Agricultura Familiar. Em: $<$ http://www.mda.gov.br/saf/arquivos/1619316242. pdf $>, 2007$. 